\title{
Traumatic Perforation of Tympanic Membrane: A Rural Profile of Bangladesh
}

\author{
Mazumder $\mathrm{JA}^{1}$, Nasir $\mathrm{SM}^{2}$, Rashid $\mathrm{S}^{3}, \mathrm{Khan} \mathrm{AM}^{4}$
}

\begin{abstract}
To determine the various etiological factors, clinical presentation and outcome of traumatic perforation of tympanic membrane (TM) in a rural area of Bangladesh. A retrospective study of 210 cases of traumatic perforation of TM in upazilla health complex, Nangalkot and Muradnagar, Comilla, Bangladesh within the period of March 2013 to February 2014. The study showed middle age people of 20-39 years age group were mostly affected (61.89\%), where males are more than females at the ratio of 1.18:1. Domestic violence was a major factor (50\%) and husbands are only culprit for $35.13 \%$ of housewives and slap was the major mode of injury (52.86\%) affecting the left ear mostly (70.95\%). Spontaneous healing rate was very satisfactory and it was $88 \%$ within 03 months in our study. Traumatic perforation of TM is a common type of injury in rural areas. Unnecessary surgical intervention or unskilled handling should be discouraged. Early appearance and watchful treatment reduces the morbidity.
\end{abstract}

Key words: Tympanic membrane, tuning fork test, audiometry, slap.

1. Corresponding Author: Dr. Jahangir Alam Mazumder Junior Consultant (ENT)

Upazilla Health Complex, Nangalkot, Comilla. e-mail: jamdr67@gmail.com.

2. Dr. Syed Mohiuddin Nasir Medical Officer,( Post graduate student of ENT) Upazilla Health Complex, Nangalkot, Comilla.

3. Dr. Shazibur Rashid Junior consultant (ENT) Upazilla Health Complex, Muradnagar, Comilla.

4. Dr. Arif Morshed Khan Junior Consultant (ENT) Upazilla Health Complex, Muradnagar, Comilla.

\section{Introduction}

Tympanic membrane(TM) is a thin, translucent partition between external acoustic meatus and the middle ear. It is oval in shape, measuring $9 \times 10 \mathrm{~mm}$. It is placed obliquely at an angle of 55 degree with the floor of the meatus
TM is an important component of sound conduction as its vibratory character is necessary for sound transmission in human beings. Perforation of TM may be caused by:

(1) Change in air pressure ( blow in the ear, blast injury, eustachian tube inflation, nitrous oxide anesthesia and hyperboric oxygen treatment.)

(2) By fluid ( syringing, caloric test, diving.)

(3) By solid objects (instrumentation, attempt to foreign body removal, match stick, hair clips and sparks of hot metal). Rupture due to air pressure change occurs mostly in the anteroinferior quadrant of TM. Atrophic segments are likely to rupture at pressure change at least $50 \%$ lower than a normal $\mathrm{TM}^{2}$. Fracture bone of skull is an important cause when the fracture line involve the attachment line of TM. Lightening strike may cause rupture as rapid heating of intracorporal gas and increased middle ear pressure ${ }^{3}$.

\section{Materials and Methods}

It is a retrospective study of 210 cases of traumatic perforation of tympanic membrane (TM) within the period of March 2013 to February 2014 in two upazilla health complexes of Comilla district namely Nangalkot and Muradnagar which are the two government primary health care settings located in rural, remote and densely populated area. In this period we have seen a total 13800 patients, out of these 210 patients were of traumatic perforation of TM $(1.52 \%)$. The included patients were presented within two weeks of injury and had no history of external or middle ear diseases.

Data were collected from OPD and IPD medical records including demographic data, date, mode of trauma, otoscopic finding, tuning fork test, kind of therapy and their result. Audiometry was not included due to shortage of facility. All patients were treated conservatively with antihistamine, antibiotics (oral and/or local in infected cases) and painkiller for 7-10 days, avoidance of letting water into the ear and self ear cleaning. No surgical interventions were done but myringoplasty were advised to those whose perforations were not healed within 03 months. The perforation is classified as 1) anterosuperior, 2) posterosuperior, 3) anteroinferior, 4) posteroinferior \& 5) central ( if involve more then one quadrant) according to location and according to size it is divided into three grades( naked eye calculation by otoscope): 1) grade I: loss of tissue less than $25 \%, 2$ ) grade II: loss of tissue 
within $25 \%-50 \%, \& 3)$ grade III: loss of tissue more than $50 \%$.

\section{Results}

Table-I: Age \&Sex distribution

\begin{tabular}{ccccccc}
\hline $\begin{array}{c}\text { Age in } \\
\text { Years }\end{array}$ & \multicolumn{2}{c}{ Male } & \multicolumn{2}{l}{ Female } & \multicolumn{2}{c}{ Total } \\
\hline & No. & \% & No. & $\%$ & No. & $\%$ \\
$0-5$ & 2 & $0.95 \%$ & 2 & $0.95 \%$ & 4 & $1.90 \%$ \\
$6-10$ & 8 & $3.81 \%$ & 7 & $3.33 \%$ & 15 & $7.14 \%$ \\
$11-20$ & 23 & $10.95 \%$ & 19 & $9.05 \%$ & 42 & $20.00 \%$ \\
$21-30$ & 44 & $20.95 \%$ & 38 & $18.09 \%$ & 82 & $39.04 \%$ \\
$31-40$ & 26 & $12.38 \%$ & 22 & $10.48 \%$ & 48 & $22.85 \%$ \\
$41-50$ & 9 & $4.29 \%$ & 5 & $2.38 \%$ & 14 & $6.67 \%$ \\
$51-60$ & 3 & $1.43 \%$ & 2 & $0.95 \%$ & 5 & $2.39 \%$ \\
Total & 115 & $54.76 \%$ & 95 & $45.23 \%$ & 210 & $100 \%$ \\
\hline
\end{tabular}

Age ranges from 2 year to 57 year with the mean age of 28.20 year. The youngest patient was of 2 year old who affected by unnoticed force by another baby while he was playfully cleaning his ear by a cotton bud. The oldest patient was of 57 year old who injured his ear by syringing by a quack doctor to remove a foreign body. $61.90 \%(n=130)$ patients were in the age group $21-40$. Out of them maximum incidence (39.05\%) was among 21-30 year age group. We found males were affected more $(54.76 \%)$ than that of females $(45.24 \%)$. Male to female ratio was 1.18:1.

Table -II: Laterality of Trauma

\begin{tabular}{ccc}
\hline Side of affected & No. of patients & Percentage \\
\hline Left & 149 & $70.95 \%$ \\
Right & 61 & $29.05 \%$ \\
Both & 00 & $00 \%$ \\
\hline
\end{tabular}

$70.95 \%(n=149)$ patients were affected in their left ear and $29.05 \%(n=61)$ patients were affected in their right ear. The predilection for the left ear may be due to the fact that slap was the major etiological factor in this series and a right handed person tends to slap the victim facing to him over the left ear. No patient were attended with two ear affected

\section{Table -III: Presenting complaints}

\begin{tabular}{ccc}
\hline Presenting complaints & No. of patients & Percentage \\
\hline Tinnitus & 161 & $76.67 \%$ \\
Aural Fullness & 131 & $62.38 \%$ \\
Hearing Loss & 120 & $57.14 \%$ \\
Vertigo & 54 & $25.71 \%$ \\
Blood & 59 & $28.09 \%$ \\
Pain & 116 & $55.24 \%$ \\
Infection & 74 & $35.23 \%$ \\
\hline
\end{tabular}

In our study majority of the patients presented with tinnitus $76.67 \% \quad(n=161)$ followed by aural fullness $62.38 \%(n=131) \&$ hearing loss $57.14 \%(n=120)$. Blood in ear canal was found in $28.09 \%(n=59)$ cases while $35.23 \%$ $(\mathrm{n}=74)$ cases attended with infection. $58 \%(\mathrm{n}=122)$ patient presented with more than one complaints.

\section{Table -IV: Aetiology}

\begin{tabular}{llll}
\hline Type of injury & Mode of injury & No. of patients & Percentage \\
\hline Assault & Slap & 111 & $52.86 \%$ \\
Iatrogenic & Faulty technique ear & 39 & $18.57 \%$ \\
& cleaning & & \\
& Syringing & 45 & $21.42 \%$ \\
Accidental & Moving agent & 3 & $1.43 \%$ \\
& (foot/cricket ball) & & \\
& Forceful blow & 2 & $0.95 \%$ \\
& RTA & 7 & $3.33 \%$ \\
& Unnoticed force by & 3 & $1.43 \%$ \\
& another person & & $00 \%$ \\
\hline
\end{tabular}

In this series most common etiological factor was slap $52.86 \%(n=111)$. Iatrogenic factors like faulty technique of ear cleaning \& syringing accounts for $18.57 \%(n=39)$ \& $21.42 \%(n=45)$ respectively. Accidental rupture of TM found in $7.02 \%(n=15)$ cases. No case of blast injury was found.

Table -V: Source of slap $(n=111)$

\begin{tabular}{ccc}
\hline Offender & No. of patients & Percentage \\
\hline Husband & 39 & $35.13 \%$ \\
Father/Mother & 05 & $4.50 \%$ \\
Siblings & 09 & $8.10 \%$ \\
Friends/Schoolmate & 16 & $14.41 \%$ \\
Miscreants & 22 & $19.81 \%$ \\
Teacher & 8 & $7.20 \%$ \\
Police & 12 & $10.81 \%$ \\
\hline
\end{tabular}

$35.13 \%(n=39)$ husbands were the main culprit for a female victim which is $18.58 \%$ of total cases. Other family members (father, mother, siblings ) were responsible for $12.60 \%(n=14)$ which is $6.66 \%$ of total cases.

\section{Table -VI: Size of perforation}

\begin{tabular}{ccc}
\hline Grade of perforation & No. of patients & Percentage \\
\hline Grade-I (loss of tissue $<25 \%$ ) & 126 & $60 \%$ \\
Grade-II (loss of tissue $25-50 \%$ ) & 72 & $34.28 \%$ \\
Grade-III (loss of tissue $>50 \%$ ) & 12 & $5.71 \%$ \\
\hline
\end{tabular}

$60 \%(n=126)$ cases of the perforations were small (gradeI) in size \& located in the inferior half of the membrane $90 \%(n=189)$. The perforation were found $28.9 \%(n=59)$ in anteroinferior quadrant, $61.90 \%(n=130)$ were in posteroinferiorquadrant, $7.62 \%(\mathrm{n}=16)$ in posterosuperior quadrant \& $2.38 \%(n=05)$ in central. No perforations were found in anteriosuperior quadrant.Spontaneous healing 
observed in $88.09 \%(n=185)$ cases at 3 months. Shortest time was 21 days and longest time was 125 days. Uninfected cases healed early than that of infected cases. Wet perforation with bloody or watery discharge accelerates the healing rate. $74.28 \%(n=156)$ were healed within 30 days, $83.33 \%(n=175)$ were healed within 60 days \& $88.09 \%(\mathrm{n}=185)$ within 90 days.

\section{Discussion}

In this series we found the young age group(21-40 years) peoples had the highest incidence which is $61.89 \%$ $(n=130)$. Out of this the maximum incidence $39.04 \%$ $(n=82)$ was among 21-30 years age group. This finding coincides with most of the similar studies ${ }^{4,5,6,7}$. Males were slightly predominated over females $(54.16 \%$ vs $45.84 \%)$ which is almost similar with other studies $5,6,7,8,9$. Afolabi et $\mathrm{al}^{10}$ found male to female ratio $-2.5: 1$ whereas Linderman et al ${ }^{11}$ showed female predominated over male. Almost all studies $^{5,7,10,12}$ showed left ear to be affected more than right. We also found the same incidence as left ear $70.95 \%$ $(n=149)$ \& right ear 29.05\% ( $n=95)$ (Table-II). The predilection for the left ear may be due to the fact that slap was the major etiological factor in this series and a right handed person tends to slap the victim facing to him over the left ear. In our study slap was the highest incidence of mode of injury (Table-III \& IV). That's why left ear incidence was more than right ear.

In our study most of the patients presented with tinnitus $76.67 \%(n=161)$, aural fullness $62.38 \%(n=131)$ \& hearing loss $57.14 \%(n=120)$ (Table-III). Level of hearing loss showed by Wani A et al ${ }^{5} \&$ Sarojamma et al ${ }^{7}$ was $58.6 \%$ $\& 48 \%$ respectively which coincide with our findings. Highest level of hearing loss showed by da Lilly-Tariah et $\mathrm{al}^{13}(94.80 \%)$ \&Afolabi et $\mathrm{al}^{10}(95.30 \%)$. Conductive type of hearing loss was measured by tuning fork test to all patients. Audiometry was not included in our study. $35.23 \%(n=74)$ cases in our study presented with infection \&Afolabi et $\mathrm{al}^{10}$ found it in $37.50 \%$ cases.

In our study physical assault (Table-IV) got the highest score $52.86 \%(\mathrm{n}=111)$ which is comparable with other renown series $5,6,7,9,10$, SM Golam Rabbani et al ${ }^{6}$ \& Sarojamma et $\mathrm{al}^{7}$ showed it $88.5 \%$ \& $50 \%$ respectively. We found no cases of perforation due to blast injury but Al-Juboori et $\mathrm{al}^{9}$, Sarojamma et $\mathrm{al}^{7}$ \&Wani A et $\mathrm{al}^{5}$ found it $16.60 \%, 4 \%$ \& $5.42 \%$ respectively. Al- Juboori et $\mathrm{al}^{9}$ conducted his study in a warfull city, Bagdad of Iraq from 2011-2013 where bomb blast was a common happening everyday which may be the fact of this high incidence.

We found husbands are the main culprit for their wives to rupture tympanic membrane by slapping $35.13 \%$. Including other family members( father, mother, siblings) slapping accounts for $48 \%$ which reflect the family disharmony including marital conflict of our study area (Table-IV, V). In Nigeria 27.5\% slapping occurred for marital conflict as showed by da Lilly-Tariah et $\mathrm{al}^{13}$. Attempt at removing foreign body, self ear cleaning with variety of objects like cotton bud, pin head, match stick and wax removal in an unskillnied manner either by the parents or the primary health care physician/quack with TM perforation was an important cause found mostly among the children similar to other studies ${ }^{2,14}$.

Like that of other studies we found small perforations (Grade-I) had the high incidence 60\% $(n=126)$ which coincided with Al- Juboori et $\mathrm{al}^{9}$ (71\%) \&Sarojamma et al ${ }^{7}(56 \%)$. Inferior half of TM involved in $90 \%(n=189)$ cases (Table-VI) \&Sarojamma et $\mathrm{al}^{7}$ showed it $96 \%$. Hempel et $\mathrm{al}^{12}$ concluded as inferior part of TM mostly affected. Wani A et $\mathrm{al}^{5}$ found grade-I perforation $36 \%$ \& grade-II perforation $63 \%$ which is almost reveres to us . Posteroinferior quadrant seems to be more vulnerable to trauma since it is more laterally placed \& more easily accessible. This is the fact that direct trauma (like ear pricking, slap) create perforation easily. In our study we found it $61.90 \%(n=130)$ \&Sarojamma et $\mathrm{al}^{7}$ found it $58 \%$. More than one quadrant (central) involved in $2.38 \%$ $(\mathrm{n}=05)$.

Most traumatic perforations have a tendency to heal spontaneously. In our study we found $88 \%(n=185)$ cases healed at 3 months which is comparable to other studies $^{4,15,16}$. Two main factors that predispose to failure of the perforation to heal are loss of tissue \& secondary infection ${ }^{10}$. Small perforations are more likely to close spontaneously than larger one ${ }^{2}$. We observed these in our study. In our study the TM healed spontaneously with prophylactic antibiotic cover \& strict observation of the instruction not to allow water or any other fluid enter into the ear. By 1-3 months follow up there was complete healing of the membrane and return to normal hearing in majority of uncomplicated cases. If the perforation fails to close spontaneously in 3-6 months (in absence of infection), surgical closure is indicated ${ }^{2}$. As all our patients in this study had conservative, non-touch technique or non-surgical treatment we referred for myringoplasty after 3 months. Wet perforation with bloody or watery discharge significantly improve the healing rate and shortened the average perforation closure time as compared with dry perforation ${ }^{8}$.

In conclusion,traumatic perforation of TM have excellent prognosis. The clinical outcome of spontaneously healing is generally associated with perforation size, etiology \& whether dry or wet. Late presentation and wrong intervention predispose to complication \& poor outcome. Social awareness is required to reduce the hearing handicap and unwanted complications.

Acknowledgement

The authors are grateful to Dr A.B.M. Golam Mostafa, exprofessor of dept. of orthopedic, Comilla medical college for kind reviewing the menuscript.

\section{References}

1. B.D.Chaurasia's Human Anatomy. $4^{\text {th }}$ edition. Dr. Krishna Garg: CBS publishers \& distributors, New Delhi, 


\section{INDIA; 2004.}

2.Toner JG, Kerr AG.Ear trauma. In:Booth JB, Kerr. Advisory AG , Grooves J, editors.Scott-Brown's Otolaryngology. 6th edition.London:Butterworths Meinemann;1997.

3.Roger F. Gray, Mourice Hawthorne. Synopsis of Otolaryngology. $5^{\text {th }}$ edition.Butterworths- Meinemann: London;1992.

4.Berger G, Finke Istein Y, Harell M. Non-explosive blast injury of the ear. J Laryngol Otol.1994;108:393-398.

5.Wani A, Rehman A, Lateef S, Malik R, Ahmed A, Ahmed W, et al. Traumatic tympanic membrane perforation: An overview. Indian J Otol. 2016;22:100-4.

6.SM Golam Rabbani, Abdur Rashid, Khaled Mahmud, M Alamgir Chowdhury, AbdurRazzak. Traumatic rupture of tympanic membrane: A study of 70 cases. Bangladesh J otorhinolaryngol. 2015;21(1):38-42.

7.Sarojamma, Saurabh Raj,H.S.Satish. A clinical study of traumatic perforation of tympanic membrane. IOSR Journal of Dental and Medical Sciences. 2014:13(4)Ver.II:24-28.

8.Lou ZC, Lou ZM, Zhang QP. Traumatic tympanic membrane perforations: a study of etiology and factor affecting outcome. Am J Otolaryngol. 2012;33(5):549-55.

9.Al-Juboori AN. Evaluation of spontaneous healing of traumatic tympanic membrane perforation. Gen Med (Los angel).2004; 2:129.
10.Afolabi OA, Aremu SK, Alabi BS, Segum-Busari S. Traumatic tympanic membrane perforation: an aetiological profile. BMC Res Notes. 2009;2:232.

11.Linderman P, Edstrom S,Grandstrom G, Jacobson S, Von Sydow C, Westin T et al. Acute traumatic tympanic membrane perforation. Cover or observe ? Arch Otolaryngol Head Neck Surg. 1987;113:1285-7.

12.Hempel JM, Becker A, Muller J, Krause E, Berghaus A, Braun T. Traumatic tympanic membrane perforation: Clinical and audiometric findings in 198 patients. OtolNeurotol. 2012 oct;33(8):1357-62.

13.Da Lilly-Tariah O B, Somefun A O. Traumatic perforation of the tympanic membrane in University of Port Harcourt Teaching Hospital, Port Harcourt, Nigeria. Niger Postgrad Med J. 2007;14:121-124.

14.Ladapo AA. Danger of foreign body in the ear. Nig med J. 1979;9(1):120-122.

15.Grif An WL Jr. A retrospective study of traumatic tympanic membrane perforation in a clinical practice. Laryngoscope. 1979;89(2):261-82.

16.Lou ZC, Hu YX, Tang YM. Prognosis outcome of the tympanic membrane flap at traumatic tympanic membrane perforation edge. ORL J OtorhinolaryngolRelat Spec. 2011;73(4):212-8. 